\title{
KNOWLEdGe and ATtitudes TowaRds the Use OF ARVS Among AduLts in Dodoma
}

\author{
By Damian, Caroline (MD4 - 2005 / 2006)
}

\section{Abstract}

\section{Objective}

To assess knowledge and attitudes towards the use of ARV drugs among adults in Dodoma urban district

\section{Study design}

Descriptive, cross-sectional community based study.

\section{Setting:}

Dodoma urban district

\section{Results}

A total of 254 adult residents of Dodoma urban were interviewed in which $96.9 \%$ and $90.2 \%$ of male and female respectively interviewed were aware of ARVs. Also, majority of respondents (75.6\%) reported to be getting information through the media such as television, radio and magazine. About $84.9 \%$ of males and $82.9 \%$ of females interviewed revealed taking ARVs improves life. Most people know that ARVs increase the body immunity and improve the quality of health among people living with HI-Virus.

\section{Conclusion \& Recommendation:}

This study shows that most people are aware of ARVs

Most of the respondents got information on ARVs from the mass media

Few respondents declared that ARVs treats HIV/AIDS; this shows that people know that there is no drug treatment for HIV/AIDS.

More education should be given on ARVs

Efforts should be made to increase the number of the centers that test and dispense drugs to cover countrywide in order to make treatment readily accessible.

More and cheaper generic drugs production should be encouraged in our local laboratories and/or pharmaceutical companies. 


\section{INTRODUCTION}

HIV/AIDS pandemic continues to be one of the prominent killer diseases in Tanzania. UNAIDS estimated that more than 40million people worldwide were living with HIV/AIDS by the end of 2004.One third of them were young people between the age of 10-24 years old. Sub-Saharan Africa is the most severely affected region with over 28 million people living with HIV/AIDS at the end of 2003. In Tanzania, it has been estimated that more than two million people are living with HIV/AIDS in 2002 [URT 2003]

In developed countries the development and the use of ARV drugs has meant an improved quality of people living with HIV/AIDS. This has brought about the dramatic decline in mortality as a result of AIDS. The introduction of highly active Antiretroviral Therapy [HAART] that is combination of at least three different ARV drugs has made it a manageable infectious disease. While HAART has made it a manageable disease, the vast majority from Sub Saharan Africa does not yet have access to this treatment because of poor knowledge on $A R V$ and the availability factor [Horn of Africa Journal of AIDS, July, 2004]

Only about 440,000 HIV/AIDS individuals in developing countries are receiving ARV drugs to improve the quality of their health. Of almost 30 million Africans living with HIV/AIDS, only 50,000 are currently being treated with ARV drugs. [UNAIDS, 2003]

Tanzania initiated the delivery of ARV drugs to Public Health Facilities in October 2004. Prior to that, few Tanzanians [about 2,000] were able to access ARVs. The plan was targeted to cover 400,000 HIV infected Tanzanians on ARV therapy in a period of five years. About
90 sites were selected to initiate ARV drugs in the first year, where by the number of patients expected to be on ARVs in their first year were 44,000 . Currently 19,590 patients are on treatment though the sites are still enrolling more patients [.NACP,2005]

The patients are detected by blood test after effective counselling when attending the VCT centres. The general community turn up to $\mathrm{VCT}$ is very poor. This may be due to negative community perceptions and poor knowledge on HIV/AIDS and related facts. ARVs used by HIV/AIDS patients have negatively being perceived by the community due to poor knowledge and negative attitudes on it hence turn up on the use has become very poor. Prevention of HIV/AIDS requires a multi-system approach, which combines basic education, social empowerment and implementation of a programme on ARV provision. As a consequence HIV/AIDS has also brought with it new challenges of how to provide care and support unique to those who fall sick and surviving family members.

To mitigate the HIV/AIDS impact on the health system, the government has adopted among other strategies, the promotion of ARV drugs use by patients with AIDS as well as for post exposure prophylaxis. Before prescribing ARV drugs patients must be tested for the presence of HI-Virus antibody and/or antigens, CD4 counts, Full Blood Picture [FBP], Liver Function Test [LFT], and counseling to patients as well as the members of the family. The drugs suppress viral replication, preserve immunity function and prolong disease free survival.

The study was aimed at assessing community knowledge and attitude towards ARV drugs used by HIV infected patients among adults.

DMSJ Vol. 14 (Suppl. 1) 


\section{METHODOLOGY}

\section{Study setting}

The study was conducted in Dodoma urban district, which is one of the five districts of Dodoma region. The study was selected purposely for convenience and priority, as is one of the areas of concern to target on the provision of ARV drugs

\section{Study design}

Descriptive cross-sectional study, which employs both qualitative and quantitative methods of data collection and analysis, was done.

\section{Study population}

Population of 12 years of age and above were targeted because they are the most affected by HIV as it has been reported by NACP, 2003 that there is increased number of reported cases in the age group 25-34 in females and 30-39 in male. The assumption is since they are most affected they may have some characteristic knowledge and different attitudes towards the use of ARVs.

A structured interview schedule was used in data collection. A Swahili questionnaire that contained both open and closed ended questions was used for data collection.

\section{Data management}

Quality check was made at the end of the day to ensure all questionnaires were properly filled. All responses were coded, entered in a computer and analyzed.

\section{RESULTS.}

TABLE 1: VARIATION IN LEVELS OF AWARENESS OF ARV DRUGS BY AGE GROUP

\begin{tabular}{|l|l|l|l|}
\hline \multirow{2}{*}{ AGE (YEARS) } & \multicolumn{2}{|l|}{ HEARD ABOUT ANTIRETROVIRAL } & \multicolumn{2}{|l|}{ TOTAL (\%) } \\
\cline { 2 - 3 } & YES (\%) & NO $(\%)$ & 55 \\
\hline $12-22$ & $55(100)$ & $0(0)$ & 93 \\
\hline $23-33$ & $89(95.7)$ & $4(4.3)$ & 56 \\
\hline $34-44$ & $53(94.6)$ & $3(5.4)$ & 30 \\
\hline $45-55$ & $29(96.7)$ & $1(3.3)$ & 14 \\
\hline $56-66$ & $9(64.3)$ & $5(35.7)$ & 5 \\
\hline $67-77$ & $3(60)$ & $2(40)$ & 1 \\
\hline $78+$ & $0(0)$ & $0(0)$ & $254(100)$ \\
\hline TOTAL & $238(93.7)$ & $16(6.3)$ & \\
\hline
\end{tabular}

Table above shows $93.7 \%$ of interviewed population were aware about ARVs and only $6.3 \%$ were not aware about ARVs. Majority of them being the age group of 23-33[95.7\%]which is the sexually active group, but the awareness decreases with older age group 
TABLE 2; VARIATION OF LEVEL OF AWARENESS OF ANTIRETROVIRAL DRUGS WITH SEX.

\begin{tabular}{|l|l|l|c|}
\hline \multirow{2}{*}{ AGE (YEARS) } & \multicolumn{2}{l|}{ HEARD ABOUT ANTIRETROVIRUS } & \multirow{2}{*}{ TOTAL (\%) } \\
\cline { 2 - 3 } & YES (\%) & NO (\%) & \\
\hline MALE & $127(96.9)$ & $4(3.1)$ & 132 \\
\hline FEMALE & $111(90.2)$ & $12(9.8)$ & 123 \\
\hline TOTAL & $238(93.7)$ & $16(6.3)$ & $254(100)$ \\
\hline
\end{tabular}

Table above shows $96.9 \%$ and $90.2 \%$ of both male and female respective interviewed were aware of ARVs. This shows that male are more aware than female which may imply that male are more knowledgeable than female

\section{TABLE 3; VARIATION OF AGE WITH THE SOURCE OF INFORMATION ABOUT ARVs}

\begin{tabular}{|c|r|r|r|r|r|r|}
\hline $\begin{array}{c}\text { AGE } \\
\text { (YEARS) }\end{array}$ & $\begin{array}{r}\text { FRIENDS/ } \\
\text { RELATIVE (\%) }\end{array}$ & $\begin{array}{r}\text { PLACE OF } \\
\text { WORK (\%) }\end{array}$ & $\begin{array}{c}\text { TV/ RADIO/ } \\
\text { MAGAZINE } \\
(\%)\end{array}$ & $\begin{array}{c}\text { SCHOOL/ } \\
\text { SEMINAR } \\
(\%)\end{array}$ & VCT (\%) & TOTAL (\%) \\
\hline $12-22$ & $6(10.9)$ & $0(0)$ & $41(74.5)$ & $7(12.7)$ & $1(1.8)$ & 55 \\
\hline $23-33$ & $15(16.9)$ & $2(2.2)$ & $66(74.2)$ & $2(2.2)$ & $4(4.5)$ & 89 \\
\hline $34-44$ & $7(13.2)$ & $0(0)$ & $40(75.5)$ & $1(1.9)$ & $5(9.4)$ & 53 \\
\hline $45-55$ & $4(13.8)$ & $1(3.4)$ & $24(82.8)$ & $0(0)$ & $0(0)$ & 29 \\
\hline $56-66$ & $1(11.1)$ & $1(11.1)$ & $6(66.7)$ & $1(11.1)$ & $0(0)$ & 9 \\
\hline $67-77$ & $0(0)$ & $0(0)$ & $3(100)$ & $0(0)$ & $0(0)$ & 3 \\
\hline TOTAL & $33(13.9)$ & $4(1.7)$ & $180(75.6)$ & $11(4.6)$ & $10(4.2)$ & $238(100)$ \\
\hline
\end{tabular}

The results shows that majority of respondents (75.6\%) get information through the media such as Television, Radio and magazine.1.7\%get information from the place of work that means less is discussed in the places of work

TABLE 4; VARIATION OF SEX WITH THE POSIBILITY OF TAKING ARVs TO IMPROVE LIFE

\begin{tabular}{|l|l|l|l|}
\hline \multirow{2}{*}{ SEX } & \multicolumn{2}{l|}{ DOES TAKING ARVS IMPROVE LIFE } & TOTAL \\
\cline { 2 - 3 } & YES $(\%)$ & NO $(\%)$ & \\
\hline MALE & $107(84.9)$ & $19(15.1)$ & $126(100)$ \\
\hline FEMALE & $92(82.9)$ & $19(17.1)$ & $111(100)$ \\
\hline TOTAL & $199(84.0)$ & $38(16)$ & $237(100)$ \\
\hline
\end{tabular}

Table above shows $84.9 \%$ of males and $82.9 \%$ of females interviewed population responds taking ARVs improves life.

DMSJ Vol. 14 (Suppl. 1)

22 
TABLE 5; VARIATION OF REASONS OF USING ARVs WITH AGE

\begin{tabular}{|l|r|r|r|r|r|}
\hline AGE (YEARS) & TREAT HIV (\%) & $\begin{array}{c}\text { INCREASE } \\
\text { BODY } \\
\text { IMMUNITY (\%) }\end{array}$ & ADVICED (\%) & $\begin{array}{r}\text { IMPROVE } \\
\text { QUALITY OF } \\
\text { HEALTH(\%) }\end{array}$ & $\begin{array}{c}\text { TOTAL } \\
(\%)\end{array}$ \\
\hline $12-22$ & $1(2.3)$ & $25(58.1)$ & $1(2.3)$ & $16(37.2)$ & $43(100)$ \\
\hline $23-33$ & $0(0)$ & $37(46.3)$ & $2(2.5)$ & $41(51.3)$ & $80(100)$ \\
\hline $34-44$ & $0(0)$ & $20(48.8)$ & $0(0)$ & $21(51.2)$ & $41(100)$ \\
\hline $45-55$ & $0(0)$ & $8(38.1)$ & $0(0)$ & $13(61.9)$ & $21(100)$ \\
\hline $56-66$ & $0(0)$ & $3(37.5)$ & $0(0)$ & $5(62.5)$ & $8(100)$ \\
\hline $67-77$ & $0(0)$ & $1(1)$ & $0(0)$ & $0(0)$ & $1(100)$ \\
\hline TOTAL & $1(0.5)$ & $94(48.5)$ & $3(1.5)$ & $96(49.5)$ & $194(100)$ \\
\hline
\end{tabular}

Table above shows that most people know that ARVs increases the body immunity and improve the quality of health among PLWHA by $48.5 \%$ and $49.5 \%$ respectively. Most of them being the age group $12-22$ who responded that it increases the body immunity and 56-66 who responded that it improves the quality of health.

The results shows that majority of respondents (75.6\%) get information through the media such as Television, Radio and magazine.1.7\%get information from the place of work that means less is discussed in the places of work

\section{TABLE 5; VARIATION OF REASONS OF USING ARVs WITH AGE}

\begin{tabular}{|l|r|r|r|r|r|}
\hline AGE (YEARS) & TREAT HIV (\%) & $\begin{array}{c}\text { INCREASE } \\
\text { BODY } \\
\text { IMMUNITY }(\%)\end{array}$ & ADVICED (\%) & $\begin{array}{r}\text { IMPROVE } \\
\text { QUALITY OF } \\
\text { HEALTH(\%) }\end{array}$ & TOTAL (\%) \\
\hline $12-22$ & $1(2.3)$ & $25(58.1)$ & $1(2.3)$ & $16(37.2)$ & $43(100)$ \\
\hline $23-33$ & $0(0)$ & $37(46.3)$ & $2(2.5)$ & $41(51.3)$ & $80(100)$ \\
\hline $34-44$ & $0(0)$ & $20(48.8)$ & $0(0)$ & $21(51.2)$ & $41(100)$ \\
\hline $45-55$ & $0(0)$ & $8(38.1)$ & $0(0)$ & $13(61.9)$ & $21(100)$ \\
\hline $56-66$ & $0(0)$ & $3(37.5)$ & $0(0)$ & $5(62.5)$ & $8(100)$ \\
\hline $67-77$ & $0(0)$ & $1(1)$ & $0(0)$ & $0(0)$ & $1(100)$ \\
\hline TOTAL & $1(0.5)$ & $94(48.5)$ & $3(1.5)$ & $96(49.5)$ & $194(100)$ \\
\hline
\end{tabular}

Table above shows that most people know that ARVs increases the body immunity and improve the quality of health among PLWHA by $48.5 \%$ and $49.5 \%$ respectively. Most of them being the age group 12-22 who responded that it increases the body immunity and 56-66 who responded that it improves the quality of health. 
TABLE 6; VARIATION IN REPORTED ARVS AVAILABILITY IN NEARBY SETTINGS BY

SEX.

\begin{tabular}{|l|l|l|l|}
\hline SEX & YES (\%) & NO (\%) & TOTAL (\%) \\
\hline FEMALE & $70(64.2)$ & $39(35.8)$ & $109(100)$ \\
\hline MALE & $88(71)$ & $36(29)$ & $124(100)$ \\
\hline TOTAL & $158(67.8)$ & $75(32.2)$ & $233(100)$ \\
\hline
\end{tabular}

Table above shows $64.2 \%$ and $71 \%$ of female and male interviewed respectively reported that ARVs were available in the nearby settings.

\section{DISCUSSION}

Out of 254 people who were involved in the study, 134 were males and 123 were female. 93.7\% of interviewed sample population were aware about antiretroviral drugs (ARVs). Majority of them $95.7 \%$ being of age group 23-33 years, which is the reproductive age group, and they are sexually active. The findings of the study showed that the level of awareness of ARVs decreases with advancing age where by only $60 \%$ of study population aged 67-77 were aware. This findings can be compared to the study done in Durban South Africa, whereby $74 \%$ of interviewed patients in a tuberculosis clinic did not know anything about ARV.[Gebrekristos 2005].

This study also showed that more males [96.9\%] were aware of ARVs than females [90.2\%]. Although NACP in 2005 reported that the highest prevalence of HIV was among women aged 15-24, this shows that though women are at high risk of getting HIV infection but they are not that much aware of ARVs compared to the males.

This study shows that the main source of information about ARVs was Media. Most of those interviewed reported to get information about ARVs and majority were in reproductive age group 12 to 44 years and they have a maximum average of $74 \%$. Therefore the media is a good source of information to reach the target population.

The study also showed that $84 \%$ of the interviewed population declared that taking ARVs improves the life of PLWHA. This finding relates with those of the study done in Soweto South Africa which also shows that $80 \%$ of interviewed adult population reported that if they were taking ARVs they would not be worried about their families or their friends [Nachega et al 2003]. As it has revealed that more males are accessible to information compared to female. Those respondents who responded that it improves life they responded to the options that it improves life by increasing the body immunity hence improving the quality of life. Only $0.5 \%$ of all the respondents respond that ARVs treats HIV/AIDS, this shows that those who have an idea on ARVs they also know how ARVs work. On the other hand those who responds that they will not advice the use of ARVs they give the reasons that, ARVs are very expensive $82.1 \%$ hence it could be difficult for them to complete the doses, cause early death $12.8 \%$ and only $5.1 \%$ that they are forbidden by the religions. Most of the respondents aged 45-55[85.7\%] respond that the ARVs are very expensive.

On the basis of the availability of the ARVs, $67.8 \%$ reported that ARVs are available in their

DMSJ Vol. 14 (Suppl. 1) 
nearby settings especially in the hospital $47.5 \%$ and $35 \%$ responded that there are found in the VCT centers.

\section{CONCLUSION}

This study showed that many people are aware of ARVs, with larger number of males than females. Age wise, those who were sexually active were found more knowledgeable. Most of them actually get information from the mass media such as Radio, Television and Magazines. Little or nothing is discussed about ARVs in the places of work because very few respondents who are working reported that they got information from their places of work.

This study has also showed that for those who were aware had thought that ARVs improved the life of PLWHA by increasing the body immunity hence improving the quality of life. Few people responded that ARV's treat HIV/ AIDS; this shows that people know that there is no drug treatment for HIV/AIDS.

It has been observed that ARVs are available in Dodoma urban district, mainly in the hospitals and in the VCT centers. Despite the availability of ARVs, it has been shown that they are however very expensive that some of the respondents could not advice their use due to the concern over adherence to treatment visà-vis cost .

\section{RECOMMENDATIONS}

Since a good number of people especially males are aware and knowledgeable of ARVs, more efforts should be done to attain also a good number of female awareness on ARVs because female have high prevalence of infections.
More education should be given on ARVs through seminars and workshops organized by Government and also the employers to their working staff since it has shown that little if anything is discussed about ARVs in the working places.

Increasing the number of the centers that test and dispense drugs to cover countrywide in order to make treatment readily available.

Price reduction on drugs can make it possible for more people to access the drugs.

More and cheaper generic drugs production should be encouraged in our local laboratories.

Reduction the reliance on donors support for the drugs treatment improve the treatment programme as it has reported from Uganda that reliance on donors support is one of the weakness of the treatment programme.

\section{ACKNOWLEDGEMENT}

My heartfelt gratitude should go to my supervisor, Mr. M. Ezekiel of Department of Behavioral Sciences, MUCHSforhis constructive criticism, guidance and encouragement throughout the period of this study.

My appreciations also go to technical review committee of MUCHS for allowing me to be sponsored for conducting the study. I am also greatly indebted to the Dodoma district and Ward executive officials for allowing me to conduct the study in their area.

It would be selfishness not to acknowledge Walter Kweka for his assistance in data entry and analysis. Carol, David and Rukia who have been very close to me especially during data collection and data managements at the end of each day of my data collection.

Above all, I thank God for his everlasting 
love and grace, for giving me strength and courage that enabled make the first step, and replenished and sustained my energy thought my school career and during this study.
Needless to say, for many of the errors and patches of ignorance that remain, the ultimate responsibility rests with me

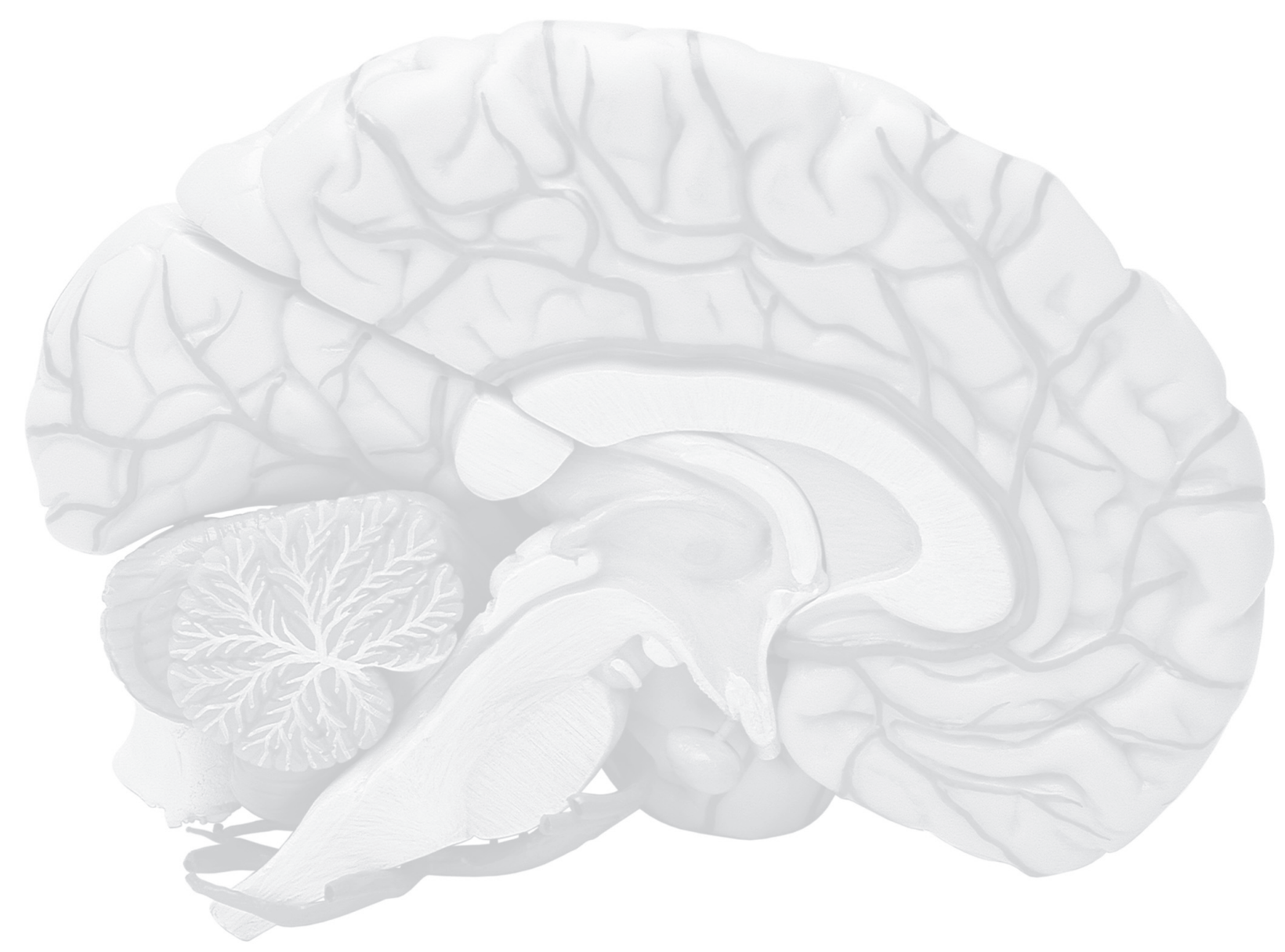

\section{References:}

NOT PROVIDED

DMSJ Vol. 14 (Suppl. 1) 